\title{
Pigment epithelium-derived factor inhibits caveolin-induced interleukin-8 gene expression and proliferation of human prostate cancer cells
}

\author{
TAKANORI MATSUI $^{1}$, AYAKO OJIMA ${ }^{1}$, YUICHIRO HIGASHIMOTO ${ }^{2}$, \\ JUNICHI TAIRA $^{2}$, KEI FUKAMI ${ }^{3}$ and SHO-ICHI YAMAGISHI ${ }^{1}$ \\ Departments of ${ }^{1}$ Pathophysiology and Therapeutics of Diabetic Vascular Complications; \\ ${ }^{2}$ Chemistry; and ${ }^{3}$ Medicine, Kurume University School of Medicine, Kurume 830-0011, Japan
}

Received October 8, 2014; Accepted July 7, 2015

DOI: $10.3892 / \mathrm{ol} .2015 .3568$

\begin{abstract}
Caveolin-1 (Cav), a primary protein component of caveolae, is overexpressed in prostate cancer, thereby promoting growth and metastasis of this tumor. By contrast, pigment epithelium-derived factor (PEDF) has been shown to inhibit tumor growth and metastasis, including that of prostate cancer, via its anti-angiogenic and anti-inflammatory effects. Although it was recently demonstrated that PEDF binds to Cav and blocks its pro-inflammatory actions in endothelial cells, it remains unclear whether PEDF also inhibits the tumor-promoting effects of Cav in cultured prostate cancer cells. The present study examined the effects of PEDF on cell growth, in addition to the gene expression of interleukin-8 (IL-8), which is involved in prostate cancer progression, in the PC-3 human prostate cancer cell line. Exogenous Cav led to a dose-dependent upregulation of the mRNA expression of IL-8 in PC-3 cells, which was blocked by treatment with 1 or $10 \mathrm{nM}$ PEDF, or following the overexpression of small interfering RNAs directed against Cav. Cav $(10 \mathrm{nM})$ increased DNA synthesis in PC-3 cells, which was again suppressed by the administration of $10 \mathrm{nM}$ PEDF. The results of the present study indicated that PEDF may inhibit Cav-induced increases in IL-8 gene expression and proliferation of PC-3 cells. Therefore, the suppressive effects of PEDF in prostate cancer may, in part, be ascribed to its inhibitory actions on Cav.
\end{abstract}

\section{Introduction}

Caveolin-1 (Cav) is an important protein component of caveolae, a specialized type of membrane lipid raft, which are involved

Correspondence to: Dr Sho-Ichi Yamagishi, Department of Pathophysiology and Therapeutics of Diabetic Vascular Complications, Kurume University School of Medicine, 67 Asahi-machi, Kurume 830-0011, Japan

E-mail: shoichi@med.kurume-u.ac.jp

Key words: Caveolin-1, pigment epithelium-derived factor, interleukin-8, prostate cancer cells, angiogenesis in multiple cellular processes, such as molecular transport, cell adhesion and signal transduction $(1,2)$. Recently, Cav has been shown to be overexpressed in prostate cancer, and to promote the growth and metastasis of this tumor (3-6). Cav has been demonstrated to activate oncogenic pathways involving Akt and to promote the proliferation of prostate cancer, in addition to stimulating tumor-associated angiogenesis and inflammation (3-6). Furthermore, in a large population study involving men with a serum prostate-specific antigen of $>10 \mathrm{ng} / \mathrm{ml}$, high pre-treatment serum levels of Cav were a prognostic marker for prostate cancer recurrence (7). Increased circulating levels of Cav were also shown to be associated with the histological grade and progression of prostate cancer $(8,9)$. These observations suggest the involvement of $\mathrm{Cav}$ in tumor growth and aggressiveness of prostate cancer.

Pigment epithelium-derived factor (PEDF) is a glycoprotein that belongs to the superfamily of serine protease inhibitors, which exhibit potent neuronal differentiating activity (10). PEDF has been identified as a highly effective inhibitor of angiogenesis in cell culture models as well as in animal models $(11,12)$. Furthermore, studies have demonstrated that PEDF blocks cytokine-induced and vascular endothelial growth factor-induced angiogenesis and inflammatory reactions, inhibits tumor growth and induces apoptosis in tumors, including prostate cancer (11-24). Our group has recently demonstrated that PEDF binds to Cav and blocks its pro-inflammatory effects in endothelial cells (25). It is therefore possible that PEDF may exert its antitumor effects in prostate cancer by modulating the actions of Cav. However, it remains unclear whether PEDF inhibits the tumor-promoting effects of Cav in cultured prostate cancer cells. The present study examined the effects of PEDF on prostate cancer cell growth and on the expression of the interleukin-8 (IL-8) gene, which contributes to prostate cancer progression in PC-3 cells, a human hormone-refractory (HRPC) cell line (17).

\section{Materials and methods}

Materials. Polyclonal anti-human rabbit antibodies (Abs) directed against Cav (cat no. 3238) and polyclonal biotin-conjugated Abs against PEDF (cat no. BAF 1177) were purchased 
from Cell Signaling Technology Japan K.K. (Tokyo, Japan) and R\&D Systems (Minneapolis, MN, USA), respectively. Monoclonal mouse anti-human Abs raised against GAPDH were obtained from Santa Cruz Biotechnology, Inc., Dallas, TX, USA (cat no. sc-32233).

Expression and purification of Cav. Full-length human Cav (residues 1-178) was amplified using polymerase chain reaction (PCR), sub-cloned into the NdeI and XhoI sites of the pET21b vector, incorporating pentahistidine-tag into the $\mathrm{C}$-terminus of the protein and purified as previously described (26). Briefly, the PCR primers for Cav were as follows: Forward, 5'-CCGGTCCATATGTCTGGGGGCAAATAC-3' and reverse, 5'-CCCCTCGAGTATTTCTTTCTGCAAGTT-3'. PCR reactions were performed using PrimeSTAR ${ }^{\circledR}$ HS (Takara Bio Inc., Shiga, Japan) and the PCR conditions were as follows: 35 cycles of $98^{\circ} \mathrm{C}$ for $10 \mathrm{sec}, 55^{\circ} \mathrm{C}$ for $10 \mathrm{sec}$ and $72^{\circ} \mathrm{C}$ for $120 \mathrm{sec}$.

Preparation of PEDF proteins. Hexahistidine-tagged PEDF proteins were purified from conditioned media using a Ni-NTA spin kit (Qiagen GmbH, Hilden, Germany), according to the manufacturer's instructions as described previously (27). SDS-PAGE analysis of the purified PEDF proteins identified a single band with a molecular mass of $\sim 50 \mathrm{kDa}$, which exhibited positive reactivity with monoclonal mouse Abs against human PEDF (cat. no. KM037; 1:1,000 dilution; Transgenic, Kumamoto, Japan).

Construction and transfection of small interfering RNAs (siRNAs). The following siRNAs to Cav (siCavs) were used: Sense, 5'-GCUUCCUGAUUGAGAUUCAtt-3' and antisense, 5'-UGAAUCUCAAUCAGGAAGCtc for siCav\#1; and sense, 5'-GCCGUGUCUAUUCCAUCUAtt-3' and antisense, 5'-UAGAUGGAAUAGACACGGCtg for siCav\#2. The siCavs were obtained from Life Technologies Japan, Ltd. (Tokyo, Japan). Non-silencing control siRNAs (siCon) were also obtained from Life Technologies Japan, Ltd. (Silencer Negative Control \#1 siRNA). The siRNA duplexes were transfected into PC-3 cells using Lipofectamine 2000 ${ }^{\mathrm{TM}}$ (Invitrogen Life Technologies, Carlsbad, CA, USA), as previously described (28). Following 2 days of transfection, Cav and GAPDH protein levels were analyzed using western blotting.

Cells. PC-3 human prostate cancer cells (American Type Culture Collection, Manassas, VA, USA) were cultured in RPMI-1640 (Sigma-Aldrich, St. Louis, MO, USA) with $10 \%$ fetal bovine serum and $100 \mathrm{U} / \mathrm{ml}$ penicillin/streptomycin (Life Technologies Japan, Ltd.). PEDF or Cav treatment was conducted in a medium containing $1 \%$ fetal bovine serum.

Reverse transcription-quantitative PCR (RT-qPCR). Transfected or non-transfected PC-3 cells were treated with or without the indicated concentrations of $\mathrm{Cav}(0.1,1$ or $10 \mathrm{nM})$, in the presence or absence of $10 \mathrm{nM}$ PEDF for $4 \mathrm{~h}$. Total RNA was then extracted using a NucleoSpin RNA kit (Takara Bio Inc.), according to the manufacturer's instructions. qRT-PCR was performed using Assay-on-Demand and TaqMan 5 fluorogenic nuclease chemistry (Life Technologies Japan Ltd.), according to the manufacturer's instructions. The IDs of the primers for human interleukin-8 (IL-8) and the $\beta$-actin gene (Applied
Biosystems Life Technologies, Foster City, CA, USA) were Hs99999034_m1 and Hs01060665_g1, respectively. RT-qPCR conditions were as follows: $50^{\circ} \mathrm{C}$ for $2 \mathrm{~min}$ and $95^{\circ} \mathrm{C} 10 \mathrm{~min}$, followed by 45 cycles of $95^{\circ} \mathrm{C}$ for $15 \mathrm{sec}$ and $60^{\circ} \mathrm{C}$ for $2 \mathrm{~min}$. The results were quantified using the $2^{-\Delta \Delta \mathrm{CT}}$ method (29).

Serum preparation. Serum was obtained from 3 individuals: A healthy 38 year-old male [body mass index (BMI), 21.1]; a 59 year-old diabetic man with cardiovascular disease (BMI, 31.1; HbAlc, 8.6\%), as PEDF levels have been shown to increase in diabetic patients (24); and a 64 year-old patient with stage II prostate cancer (BMI unknown). All prostate cancer patient serum speciemens were purchased from Tissue Solutions Ltd., Glasgow, UK.

Western blotting analysis. Proteins were extracted from siCon- or siCav-transfected PC-3 cells, using lysis buffer as previously described (28). The samples or serum were then separated by SDS-PAGE and transferred to nitrocellulose membranes (Life Technologies Japan, Ltd.). Membranes were probed with Abs against Cav (1:1,000 dilution), PEDF (1:1,000 dilution) or GAPDH (1:200 dilution) for $12 \mathrm{~h}$ at room temperature, and then incubated with peroxidase-conjugated polyclonal donkey anti-rabbit IgG Abs (1:20,000 dilution; cat no. NA934-100UL; GE Healthcare UK Ltd., Little Chalfont, UK), streptavidin-conjugated peroxidase $(1: 5,000)$ or polyclonal sheep anti-mouse Abs (1:20,000 dilution; cat no. NA931-100UL; GE Healthcare UK Ltd.), respectively. Immune complexes were visualized using an enhanced chemiluminescence detection system (Amersham Bioscience, Buckinghamshire, UK). The protein signals were quantified using Image J software (version 1.46; National Institutes of Health, Bethesda, MD, USA). The $\mathrm{Cav}$ protein levels of each sample were normalized to those of GAPDH.

Measurement of $\left[{ }^{3} \mathrm{H}\right]$ thymidine incorporation into PC-3 cells. PC-3 cells were treated with or without $10 \mathrm{nM} \mathrm{Cav,} \mathrm{in} \mathrm{the}$ presence or absence of $10 \mathrm{nM}$ PEDF for $20 \mathrm{~h}$. Subsequently, $\left[{ }^{3} \mathrm{H}\right]$ thymidine was added, to produce a final concentration of $1 \mathrm{mCi} / \mathrm{ml}$, and cells were incubated for a further $4 \mathrm{~h}$. Following incubation, PC-3 cells were fixed with ice-cold $10 \%$ (w/v) trichroloacetic acid for $20 \mathrm{~min} .\left[{ }^{3} \mathrm{H}\right]$ thymidine incorporation into PC-3 cells was measured as described previously (30). Briefly, $\left[{ }^{3} \mathrm{H}\right]$ thymidine incorporation into PC-3 cells was measured by processing the resultant acid-insoluble materials for liquid scintillation counting (AccuFLEX LSC 7200; Hitachi Aloka Medical, Ltd., Tokyo, Japan).

Statistical analysis. Data are presented as the mean \pm standard error. Student's t-test was performed for statistical comparisons. All statistical analyses were performed using PASW Statistics version 18.0 software (SPSS Japan Inc., Tokyo, Japan) and $\mathrm{P}<0.05$ was considered to indicate a statistically significant difference.

\section{Results}

Cav leads to upregulation of IL-8 expression in PC-3 cells and this effect is abrogated by PEDF. The effect of PEDF on IL-8 gene expression in Cav-exposed PC-3 cells was 
A

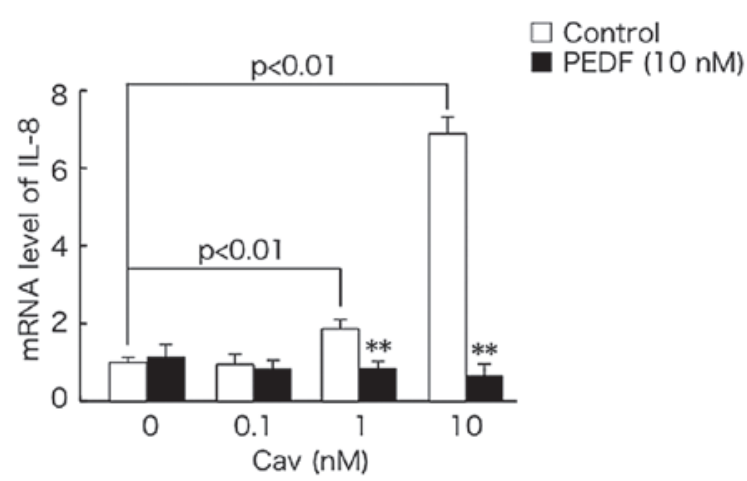

B

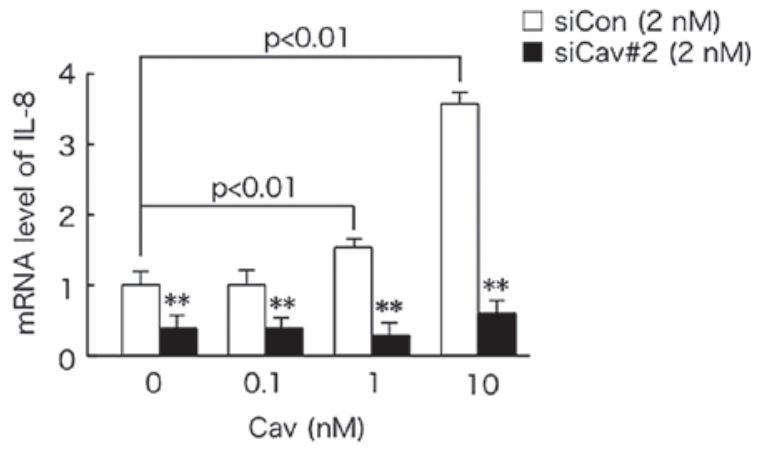

C

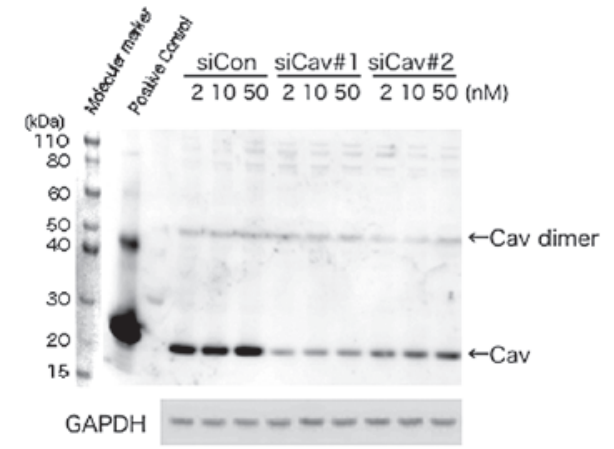

Figure 1. Effect of PEDF on IL-8 gene expression in PC-3 cells. (A) Non-transfected or (B) transfected PC-3 cells were treated with or without the indicated concentrations of Cav, in the presence or absence of $10 \mathrm{nM}$ PEDF for $4 \mathrm{~h}$. (A and B) Total RNA was transcribed and amplified by reverse transcription-quantitative polymerase chain reaction. Data were normalized to the level of $\beta$-actin, and then compared with the control value without PEDF (A) or to the value obtained with siCon treatment alone (B). ${ }^{* *} \mathrm{P}<0.01$, compared with the group without PEDF (A) or with the siCon group (B). $n=4$ (C) Proteins were extracted from transfected PC-3 cells. Western blot analysis was performed using anti-Cav antibodies. PEDF, pigment epithelium-derived factor; IL-8, interleukin-8; Cav, caveolin-1; siCon, small interfering control RNA; siCav, siRNA to Cav.

investigated. As shown in Fig. 1A, exogenously administered Cav upregulated the mRNA expression of IL-8 in PC-3 cells, in a dose-dependent manner. This effect was abrogated by treatment with 1 or $10 \mathrm{nM}$ PEDF.

Cav increased IL-8 mRNA expression in siCon-transfected cells, in a dose-dependent manner and this effect was suppressed by siCav\#2 transfection (Fig. 1B). Furthermore, transfection with siCav\#1 or siCav\#2, reduced Cav expression in PC-3 cells to $1 / 5-1 / 10$ of that of the siCon-transfected control cells (Fig. 1C).

PEDF leads to decreased DNA synthesis in PC-3 cells. The effect of PEDF on DNA synthesis in PC-3 cells was also
A

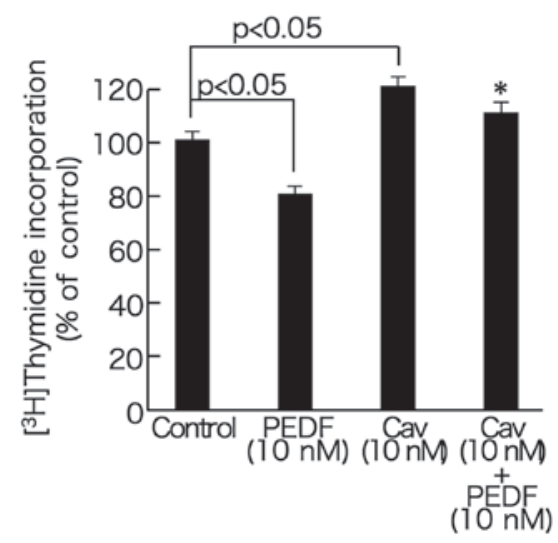

B

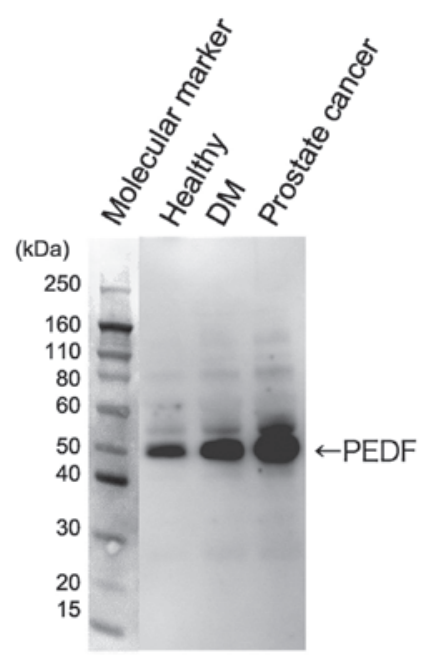

Figure 2. Effect of PEDF on DNA synthesis in PC-3 cells (A) and circulating PEDF levels in three subjects (B). (A) PC-3 cells were treated with or without $10 \mathrm{nM} \mathrm{Cav}$, in the presence or absence of $10 \mathrm{nM}$ PEDF for $20 \mathrm{~h}$. Subsequently, $\left[{ }^{3} \mathrm{H}\right]$ thymidine was added, to produce a final concentration of $1 \mu \mathrm{Ci} / \mathrm{ml}$, and cells were further incubated for $4 \mathrm{~h}$. Following incubation, PC-3 cells were fixed, and $\left[{ }^{3} \mathrm{H}\right]$ thymidine incorporation into PC-3 cells was measured. ${ }^{*} \mathrm{P}<0.05$, compared with the $10 \mathrm{nM}$ Cav alone group. $\mathrm{n}=4$. (B) Serum was separated using SDS-PAGE and transferred to nitrocellulose membranes. Membranes were then probed with antibodies against PEDF. PEDF, pigment epithelium-derived factor; Cav, caveolin-1; DM, diabetes mellitus.

examined. As shown in Fig. 2A, $10 \mathrm{nM}$ Cav significantly increased DNA synthesis in PC-3 cells. This effect was inhibited by treatment with $10 \mathrm{nM}$ PEDF. PEDF $(10 \mathrm{nM})$ also significantly decreased DNA synthesis in PC-3 cells when administered alone.

Finally, the circulating levels of PEDF in the serum of the patient with prostate cancer were higher than those of the healthy control or the diabetic subjects (Fig. 2B).

\section{Discussion}

There is accumulating evidence that overexpression of Cav promotes tumor growth and metastasis of prostate cancer via diverse pathways (3-6), while PEDF may protect against the progression of prostate cancer, via anti-angiogenic, anti-inflammatory and proapoptotic effects (17-19). To the best of our knowledge, the present study demonstrated for the first time that treatment with 1 or $10 \mathrm{nM}$ PEDF significantly inhibited the Cav-induced increase in IL-8 mRNA expression in PC-3 
cells. Transfection with siCav\#2 reduced endogenous Cav expression in PC-3 cells to $\sim 1 / 5$ of that of siCon-transfected cells, and decreased IL-8 mRNA expression in Cav-exposed PC-3 cells. Our group has recently demonstrated that PEDF directly binds to Cav at a $K_{\mathrm{D}}$ value of $7.36 \times 10^{-7} \mathrm{M}$; that exogenously administered $\mathrm{Cav}$ is taken up into endothelial cells, resulting in increases in the membrane levels of Cav and promoting inflammatory reactions; and that siCav\#1 treatment reduces Cav expression and suppresses inflammatory gene expression in endothelial cells (25). These observations indicate that PEDF may reduce Cav-induced IL-8 gene expression by binding to exogenously administered Cav and modulating its membrane levels in PC-3 cells, a type of hormone-refractory prostate cancer (HRPC) cell. IL-8 may promote the transition of prostate cancer to HRPC by upregulating androgen receptor expression and activation, and may stimulate the proliferation and migration of this cell type (17). Circulating Cav levels have been shown to be increased in patients with HRPC, while they were not increased in those with hormone-sensitive cancer (9). These findings further support the hypothesis that PEDF may inhibit the growth and metastasis of HRPC cells, such as PC-3 cells, by blocking Cav-evoked IL-8 overexpression.

The present study also demonstrated that PEDF inhibited the Cav-induced increase in DNA synthesis in PC-3 cells. Treatment with PEDF alone also decreased $\left[{ }^{3} \mathrm{H}\right]$ thymidine incorporation into PC-3 cells. Therefore, PEDF may directly inhibit the proliferation of PC-3 cells via modulation of the growth-promoting activity of Cav.

To the best of our knowledge, the current study also demonstrated for the first time that circulating PEDF levels were higher in a patient with prostate cancer, compared with levels in the healthy control or diabetic subjects. As reported previously (31), PEDF levels in diabetic subjects were higher than those in healthy controls. The antitumor effects of PEDF that were observed in the present study, suggest that circulating PEDF levels may be elevated as a counter-system against $\mathrm{Cav}$ overexpression in prostate cancer. Treatment with Cav antisera reduced the development and growth of primary tumors and metastases in mouse models of prostate cancer (32). Since it has been demonstrated that the laminin receptor mediates the anti-inflammatory and antithrombogenic effects of PEDF in malignant myeloma cells (33), blockade of the effects of Cav using a PEDF-laminin receptor system may be a novel therapeutic approach for prostate cancer.

It has previously been reported that the human blood concentration of PEDF is 100-200 nM (31,34). However, the majority of circulating PEDF in serum may exist as a protein-bound and inactive from, and the free active form of PEDF comprises only a small portion of the total level do of this protein (31). In addition, a $4 \mathrm{nM}$-increase in serum PEDF levels has been shown to exert anti-inflammatory effects in animal models $(35,36)$. Therefore, it is unlikely that PEDF at $10 \mathrm{nM}$ would produce toxic effects on PC-3 cells. Recently, serum levels of Cav were demonstrated to be increased in patients with prostate cancer compared with healthy controls. Serum levels of Cav were highest in those in the advanced stages of prostate cancer (8). Furthermore, epithelial cell hyperplasia in the prostate, in association with increased angiogenesis, was observed in PEDF-deficient mice (16). The present results support the involvement of an interaction between PEDF and Cav in prostate cancer progression in vivo.

\section{Acknowledgements}

This study was supported by Grants-in-Aid for Scientific Research (B) from the Ministry of Education, Culture, Sports, Science and Technology, Japan (grant no. 25293127).

\section{References}

1. Sowa G: Caveolae, caveolins, cavins and endothelial cell function: new insights. Front Physiol 2: 120, 2102.

2. Guan TH, Chen G, Gao B, Janssen MR, Uttarwar L, Ingram AJ and Krepinsky JC: Caveolin-1 deficiency protects against mesangial matrix expansion in a nouse model of type 1 diabetic nephropathy. Diabetologia 56: 2068-2077, 2013.

3. Thompson TC, Tahir SA, Li L, Watanabe M, Naruishi K, Yang G, Kadmon D, Logothetis CJ, Troncoso P, Ren C, et al: The role of caveolin-1 in prostate cancer: clinical implications. Prostate Cancer Prostatic Dis 13: 6-11, 2010.

4. Freeman MR, Yang W and Di Vizio D: Caveolin-1 and prostate cancer progression. Adv Exp Med Biol 729: 95-110, 2012.

5. Li L, Ren C, Yang G, Goltsov AA, Tabata K and Thompson TC: Caveolin-1 promotes autoregulatory, Akt-mediated induction of cancer-promoting growth factors in prostate cancer cells. Mol Cancer Res 7: 1781-1791, 2009.

6. Tahir SA, Yang G, Goltsov AA, Watanabe M, Tabata K, Addai J, Fattah el MA, Kadmon D and Thompson TC: Tumor cell-secreted caveolin-1 has proangiogenic activities in prostate cancer. Cancer Res 68: 731-739, 2008.

7. Tahir SA, Frolov A, Hayes TG, Mims MP, Miles BJ, Lerner SP, Wheeler TM, Ayala G, Thompson TC and Kadmon D: Preoperative serum caveolin-1 as a prognostic marker for recurrence in a radical prostatectomy cohort. Clin Cancer Res 12: 4872-4875, 2006.

8. Gumulec J, Sochor J, Hlavna M, Sztalmachova M, Krizkova S, Babula P, Hrabec R, Rovny A, Adam V, Eckschlager T, et al: Caveolin-1 as a potential high-risk prostate cancer biomarker. Oncol Rep 27: 831-841, 2012.

9. Sugie S, Mukai S, Tsukino H, Toda Y, Yamauchi T, Nishikata I, Kuroda Y, Morishita K and Kamoto T: Increased plasma caveolin-1 levels are associated with progression of prostate cancer among Japanese men. Anticancer Res 33: 1893-1897, 2013.

10. Tombran-Tink J, Chader CG and Johnson LV: PEDF: A pigment epithelium-derived factor with potent neuronal differentiative activity. Exp Eye Res 53: 411-414, 1991.

11. Dawson DW, Volpert OV, Gillis P, Crawford SE, Xu H, Benedict W and Bouck NP: Pigment epithelium-derived factor: a potent inhibitor of angiogenesis. Science 285: 245-248, 1999.

12. Duh EJ, Yang HS, Suzuma I, Miyagi M, Youngman E, Mori K, Katai M, Yan L, Suzuma K, West K, et al: Pigment epithelium-derived factor suppresses ischemia-induced retinal neovascularization and VEGF-induced migration and growth. Invest Ophthalmol Vis Sci 43: 821-829, 2002.

13. Yamagishi S, Amano S, Inagaki Y, Okamoto T, Takeuchi M and Inoue H: Pigment epithelium-derived factor inhibits leptin-induced angiogenesis by suppressing vascular endothelial growth factor gene expression through anti-oxidative properties. Microvasc Res 65: 186-190, 2003.

14. Yamagishi S, Nakamura K, Matsui T, Inagaki Y, Takenaka K, Jinnouchi Y, Yoshida Y, Matsuura T, Narama I, Motomiya Y, et al: Pigment epithelium-derived factor inhibits advanced glycation end product-induced retinal vascular hyperpermeability by blocking reactive oxygen species-mediated vascular endothelial growth factor expression. J Biol Chem 281: 20213-20220, 2006.

15. Matsui T, Nishino Y, Maeda S and Yamagishi S: PEDF-derived peptide inhibits corneal angiogenesis by suppressing VEGF expression. Microvasc Res 84: 105-108, 2012.

16. Doll JA, Stellmach VM, Bouck NP, Bergh AR, Lee C, Abramson LP, Cornwell ML, Pins MR, Borensztajn J and Crawford SE: Pigment epithelium-derived factor regulates the vasculature and mass of the prostate and pancreas. Nat Med 9: 774-780, 2003. 
17. Hirsch J, Johnson CL, Nelius T, Kennedy R, Riese Wd and Filleur S: PEDF inhibits IL8 production in prostate cancer cells through PEDF receptor/phospholipase A2 and regulation of NFKB and PPAR $\gamma$. Cytokine 55: 202-210, 2011.

18. Mirochnik Y, Aurora A, Schulze-Hoepfner FT, Deabes A, Shifrin V, Beckmann R, Polsky C and Volpert OV: Short pigment epithelial-derived factor-derived peptide inhibits angiogenesis and tumor growth. Clin Cancer Res 15: 1655-1663, 2009.

19. Gong Q, Qiu S, Li S, Ma Y, Chen M, Yao Y, Che D, Feng J, Cai W, Ma J, et al: Proapoptotic PEDF functional peptides inhibit prostate tumor growth-A mechanistic study. Biochem Pharmacol 92: 425-437, 2014.

20. Abe R, Shimizu T, Yamagishi S, Shibaki A, Amano S, Inagaki Y, Watanabe H, Sugawara H, Nakamura H, Takeuchi M, et al: Overexpression of pigment epithelium-derived factor decreases angiogenesis and inhibits the growth of human malignant melanoma cells in vivo. Am J Pathol 164: 1225-1232, 2004.

21. Takenaka K, Yamagishi S, Jinnouchi Y, Nakamura K, Matsui T and Imaizumi T: Pigment epithelium-derived factor (PEDF)-induced apoptosis and inhibition of vascular endothelial growth factor (VEGF) expression in MG63 human osteosarcoma cells. Life Sci 77: 3231-3241, 2005.

22. Seki R, Yamagishi S, Matsui T, Yoshida T, Torimura T, Ueno T, Sata $M$ and Okamura T: Pigment epithelium-derived factor (PEDF) inhibits survival and proliferation of VEGF-exposed multiple myeloma cells through its anti-oxidative properties. Biochem Biophys Res Commun 431: 693-697, 2013.

23. Hoshina D, Abe R, Yamagishi SI and Shimizu H: The role of PEDF in tumor growth and metastasis. Curr Mol Med 10: 292-295, 2010.

24. Yamagishi S and Matsui T: Pigment epithelium-derived factor (PEDF) and cardiometabolic disorders. Curr Pharm Des 20: 2377-2386, 2014.

25. Matsui T, Higashimoto Y, Taira J and Yamagishi S: Pigment epithelium-derived factor (PEDF) binds to caveolin-1 and inhibits the pro-inflammatory effects of caveolin-1 in endothelial cells. Biochem Biophys Res Commun 441: 405-410, 2013.

26. Taira J and Higashimoto Y: Caveolin-1 interacts with protein phosphatase 5 and modulates its activity in prostate cancer cells. Biochem Biophys Res Commun 431: 724-728, 2013.

27. Yamagishi S, Inagaki Y, Amano S, Okamoto T, Takeuchi $\mathrm{M}$ and Makita Z: Pigment epithelium-derived factor protects cultured retinal pericytes from advanced glycation end product-induced injury through its antioxidative properties. Biochem Biophys Res Commun 296: 877-882, 2002.
28. OjimaA,Ishibashi Y,Matsui T, Maeda S,Nishino Y,TakeuchiM, Fukami K and Yamagishi S: Glucagon-like peptide-1 receptor agonist inhibits asymmetric dimethylarginine generation in the kidney of streptozotocin-induced diabetic rats by blocking advanced glycation end product-induced protein arginine methyltranferase-1 expression. Am J Pathol 182: 132-141, 2013.

29. Livak KJ and Schmittgen TD: Analysis of relative gene expression data using real-time quantitative PCR and the 2(-Delta Delta C(T)) Method. Methods 25: 402-408, 2001.

30. Higashimoto Y, Matsui T, Nishino Y, Taira J, Inoue H, Takeuchi $\mathrm{M}$ and Yamagishi S: Blockade by phosphorothioate aptamers of advanced glycation end products-induced damage in cultured pericytes and endothelial cells. Microvasc Res 90: 64-70, 2013.

31. Yamagishi S, Adachi H, Abe A, Yashiro T, Enomoto M, Furuki K, Hino A, Jinnouchi Y, Takenaka K, Matsui T, et al: Elevated serum levels of pigment epithelium-derived factor in the metabolic syndrome. J Clin Endocrinol Metab 91: 2447-2450, 2006

32. Tahir SA, Yang G, Ebara S, Timme TL, Satoh T, Li L, Goltsov A, Ittmann M, Morrisett JD and Thompson TC: Secreted caveolin-1 stimulates cell survival/clonal growth and contributes to metastasis in androgen-insensitive prostate cancer. Cancer Res 61: 3882-3885, 2001.

33. Matsui T, Higashimoto Y and Yamagishi S: Laminin receptor mediates anti-inflammatory and anti-thrombogenic effects of pigment epithelium-derived factor in myeloma cells. Biochem Biophys Res Commun 443: 847-851, 2014.

34. Petersen SV, Valnickova Z and Enghild JJ: Pigment epithelium-derived factor (PEDF) occurs at a physiologically concentration in human blood: purification and characterization. Biochemical J 374: 199-206, 2003.

35. Fujimura T, Yamagishi S, Ueda S, Fukami K, Shibata R, Matsumoto Y, Kaida Y, Hayashida A, Koike K, Matsui T, et al: Administration of pigment epithelium-derived factor (PEDF) reduces proteinuria by suppressing decreased nephrin and increased VEGF expression in the glomeruli of adriamycin-injected rats. Nephrol Dial Transplant 24: 1397-1406, 2009.

36. Matsui T, Nishino Y, Ojima A, Maeda S, Tahara N and Yamagishi S: Pigment epithelium-derived factor improves metabolic derangements and ameliorates dysregulation of adipocytokines in obese type 2 diabetic rats. Am J Pathol 184: 1094-1103, 2014. 